\title{
The PAGES Football Cup 2017
}

Kseniia Ashastina ${ }^{1,2}$ and Stella Alexandroff ${ }^{3}$

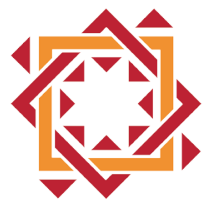

PAGES Zaragoza 2017

5th Open Science Meeting

Global Challenges for our Common Future a paleoscience perspective

The PAGES Open Science Meeting 2017 was a great conference all around - an exciting scientific program, a labyrinth of rooms and talks, great meals, networking to Spanish rhythms with red wine and a full moon. It was easy to get carried away by science rushing from one talk to the next. But two things were cemented in every head: (1) Daily lunch from 13:00-15:00 and (2) the PAGES Football Cup on 10 May at 19:30. For two days, the OSM was buzzing with questions like "Are you playing?", "In which team?", "Free beer, really?"

If you believe the common paleoscientist stereotypes, you may be forgiven for thinking that the "Proxies" scientists could have a certain advantage over the "Modelers" when it comes to outdoor sports. After all, you may picture the Modelers as physicssavvy beings who shy away from the sun and tell each other jokes in binary code. The Proxies, on the other hand, will sleep strapped to a tree branch, take their daily shower in the mud and keep confusing the words projection and prediction.

But stereotypes are stereotypes, and not suitable to predict (or project) the outcome of a football game.

The match started off very even and both teams moved gracefully on the somewhat bumpy grass pitch. It was a majestic chain of pursuit: players chased the ball, biting insects chased the players, and everyone chased free beer. While the game stayed close and suspenseful for most of its duration, it eventually became evident that the Modelers were going to win. As spectacular as some of the Proxies' goals were - one of them was a mere by-product of the attacker stumbling over the ball and falling

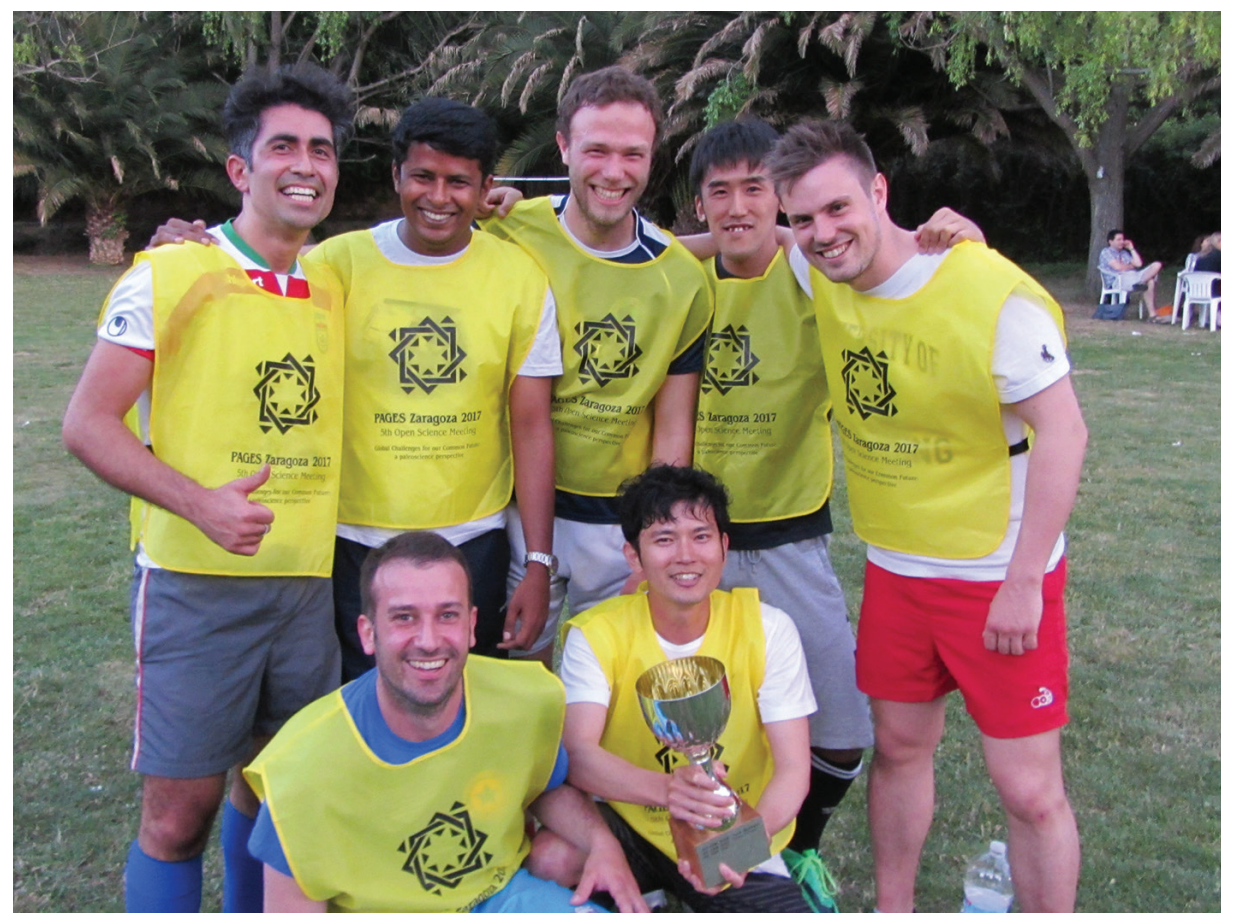

Happy winners - team Modelers - of the PAGES Football Cup 2017, 10 May, Zaragoza, Spain.

flat on the face - the Modelers played their way to a deserved win. In one blow, stereotypes were shattered, the Proxies' dreams were shattered, and everyone's skin was shattered by insects. At this point, it might be worth mentioning that the Modelers team largely consisted of Proxies, as not enough Modelers had signed up to play sports in the first place.

All in all, the football cup was a great success; everybody left the pitch in a good mood after a fun evening and ready to tackle the talks and posters of the following day.
Please see some additional facts in graphic form (accuracy of information might have been affected by euphoria) ...

\section{AFFILIATIONS}

'Senckenberg Research Station of Quaternary Palaeontology, Weimar, Germany

${ }^{2}$ Institute for Systematic Botany, Friedrich Schiller University, Jena, Germany

${ }^{3}$ School of Ocean Sciences, Bangor University, UK

\section{CONTACT}

Kseniia Ashastina: kseniia.ashastina@senckenberg.de

\section{Fans attention and excitement}

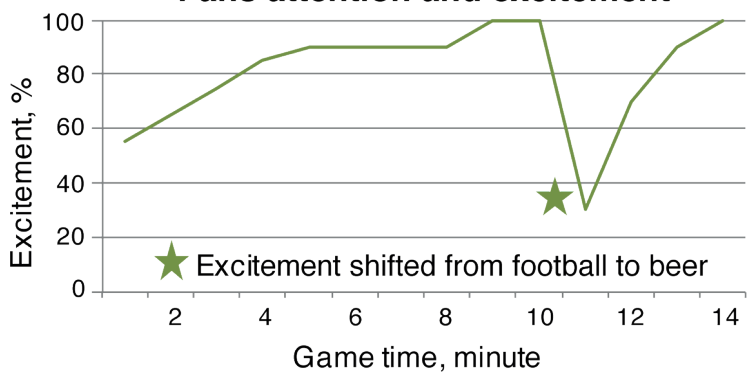

T-shirt number that scored

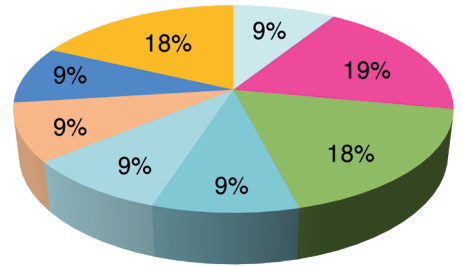

$\square 1 \square 2 \square 3 \square 4 \square 5 \square 6 \square 7 \square 8$
Gender distribution in teams

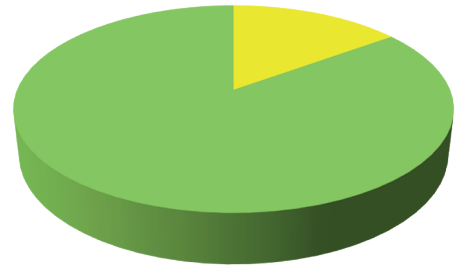

Female $\backsim$ Male 